\title{
FIRM TRANSFORMATION: ADVANCING A DARWINIAN PERSPECTIVE
}

\author{
(Colin Jones) \\ University of Tasmania \\ Faculty of Commerce \\ Private Bag 16 \\ Hobart TAS 7001 Australia \\ Phone: +61 362262826 \\ Fax: +61362262808 \\ Email: Colin.Jones@utas.edu.au
}

\begin{abstract}
ABSRACT
Purpose of the paper: The paper advocates a Darwinian explanation of the process of firm transformation. Existing, but generally opposing views related to the selection - adaptation debates are united to consider the dialogic nature of both approaches. It is argued that a Darwinian approach, as opposed to a neo-Darwinian or Lamarckian approach provides the means to scale the sides of a debate that has for too long divided scholars interested in firm and industry transformation.
\end{abstract}

Approach: The paper addresses three specific issues to develop its Darwinian argument. Firstly, the various work of Geoff Hodgson that have for many years advanced Darwin's evolutionary ideas are used to argue the nature and application of Darwinism in the socio-economic domain. Secondly, the nature of what constitutes the elements of firm-environment interaction is considered to establish basic areas of focus through which the process of firm transformation is more understandable. Lastly, the construct absorptive capacity is likened to a mechanism of transmission through which the learning processes associated with the acquisition of favoured variations can be reconciled with the generic evolutionary processes of variation, selection, and retention.

Findings: To understand the process of firm learning, the role of habits and routines must be outlined in specific detail. They cannot be assumed to perform interacting and replicating roles simultaneously. To do so, undermines the fundamental qualities of an evolutionary theory.

What is the original/value of paper: The preliminary framework advanced takes us beyond the Darwinian - Lamarckian debate and provides elements of focus from which a greater understanding of the process of firm/industry transformation is possible.

KEY WORDS: Firm Transformation, Darwinism, Lamarckism, and Absorptive Capacity

\section{INTRODUCTION}

Focussing upon the organizational change literature dealing with adaptation and selection, this paper explores the relatively unexplored middle ground of this literature. Essentially, this paper seeks to develop a framework for conceptualising an 
evolutionary theory that explains both the relationship and similarity between NeoDarwinian and Lamarckian evolution. While aspects of this ground have been explored previously (e.g. Levinthal, 1991; Amburgey, Kelly, \& Barnett, 1993; Haveman, 1992), this paper proposes that the actual role performed by organizational routines (and habits) does not explicitly include firm/environment interaction. Given that organizational routines are central to the processes that facilitate the development of knowledge through which firms attempt transformation, the question of whether routines actually perform both the role of replicators and interactors is important. In considering this issue, this paper is structured into three parts. Firstly this paper will consider the nature of the adaptation and selection debate. Secondly, it will consider the implications for organizational routines that arise from adopting a Darwinian perspective. Thirdly, it will propose that the absorptive capacity construct is a mechanism through which an enhanced explanation of the transmission and infusion of advantageous variations is possible. The aim of this discussion is to advance the development of an evolutionary framework for considering the process of firm transformation.

Since Charles Darwin's inspiration by the Malthus (1826) specter that increasing populations must ultimately combat the stinginess of nature, theories of natural selection have gained acceptance in the social sciences. However, the concept of natural selection provides only half of the story. It tends to encourage a focus upon foundings and disbandings (e.g. Hannan \& Freeman, 1989) to explain organizational and population change, focusing less upon the adaptation of existing firms (Aldrich, 1999). By contrast, supposedly 'non-Darwinian' or Lamarckian theories that seek to explain adaptive behaviours (e.g. Nelson \& Winter, 1982) from a process, rather than an event perspective, also have gained acceptance. The difference that lies between Darwinian and Lamarckian explanations can be expressed as follows. For Darwin, the ordering activity of the environment (natural selection) is preceded by variation within a population. The outcome will be the "preservation of favourable variations and the rejection of injurious variation" (Darwin, 1901:58). While for Lamarckism, variation is a function of the environment (Hodgson, 1993) with acceptance of "both the inheritance of acquired characteristics and the timely appearances of variation under the stimulus of adversity" (Nelson \& Winter, 1982:11). Importantly, Lamarckism does assume beneficial progress, given that acquired characteristics could prove to be either beneficial or detrimental.

\section{CALLS FOR UNIFICATION}

That these two main evolutionary approaches ${ }^{1}$ should be considered mutually exclusive has been the subject of recent debate (Hodgson, 2001; Knudsen, 2001). Within this debate, it has been argued convincingly by Hodgson (2001; 2003a) and Gould (2002) that Darwin was in fact tolerant of Lamarckian evolution. This provides the basis of a unification argument made on two grounds. Firstly, that from a social evolution perspective, it is possible to acquire (i.e. learn) characteristics that may prove to be beneficial (or not as the case may be). Secondly, little difference exists between the causal structures of Lamarckian and Darwinian selection processes. Because the focus of the discussion is socio-economic evolution, rather than biotic evolution, there is no need to remain bound by the rejection or acceptance of one particular evolutionary viewpoint. Within socio-economic evolution both forms of evolution are acceptable and can be accommodated within a Darwinian approach.

\footnotetext{
${ }^{1}$ The contributions of Schumpeter and Hayek to evolutionary thought are not ignored, but simply not included due to their incompatibility with pure Darwinism.
} 
The key is the pursuit of a causal explanation that explains how change occurs within a complex system involving mechanisms of variation, selection, and retention (or inheritance) (Hodgson, 2003b).

The contributions of Hodgson enable extreme positions within the adaptation and selection debate to be bypassed. As such, a plausible and unified explanation becomes possible through consideration of the interacting (rather than opposing) characteristics of neo-Darwinian and Lamarckian evolution. Given that this paper aims to consider a purely Darwinian theory, it is perhaps sensible remove any confusion that may exist regarding the terms neo-Darwinian and Darwinian. The term neo-Darwinian has existed since Darwin's protégé George Romanes used it to describe those who explicitly rejected the possibility of the inheritance of acquired characteristics as being "more Darwinian than Darwin" (Wilkins, 2001:161-162). Within the domain of socio-economic evolution, Weismannism is the term used to describe the neo-Darwinist position that denies "the possibility of the (genotypic) inheritance of acquired (phenotypic) characters" (Hodgson, 2001:95). Essentially, the mechanisms through which organizational structures are created remain unaltered through interaction with the operating environment. This view is more in line with the process of natural selection operating upon firms within a given population. Alternatively, Darwinism is a causal explanation of the evolutionary change occurring within complex systems that involve "the inheritance of genotypic instructions by individual units, a variation of genotypes, and a process of selection of the consequent phenotypes according to their fitness in their environment" (Hodgson, 2001:95). From this perspective, we can move away from the position that Weismannism and Lamarckism are mutually exclusive. We can work towards a more intuitive, and more Darwinian explanation of the processes of firm transformation that embodies both Weismannian and Lamarckian processes. From this perspective, Lamarckian evolution nests within a Darwinian framework that also accommodates the process of natural selection (Hodgson, 2001; Knudsen, 2001). It is not environmental elements (i.e. political, economic, socio-cultural, technological, and international forces) that purely determine fitness, but rather the interplay between the environment and the firm's activities, products and services, and identity, that are subject to internal change from time to time. Firms with a degree of fit may or may not survive depending upon the origins and preservation of such fit. Alternatively, firms experiencing a degree of maladjustment may indeed survive through their ability to adapt.

What is clear from this position is that selection processes occur at multiple levels. Most importantly, they occur both inside and outside the firm. Knudsen (2002) has proposed the existence of a baseline through which adaptive behaviours can be reconciled against the process of natural selection. From this perspective, the process of Lamarckian evolution can be seen as guided by the awareness of external pressures associated with the interaction the firm's activities, products and services and identity have with the environment. While both the Lamarckian and Weismannian processes share a common Darwinian causal structure, the processes are not of equal strength, given the relative position of any individual typical firm vis-à-vis its operating environment. Therefore, it is logical that repeated successful adaptive behaviours are able to be reconciled against a baseline that limits the degree of change. A limitation to this idea is the problem of evaluating a changing baseline against a rapidly changing environment. Under such conditions, it is challenging to envisage how a meaningful evaluation of positive or negative outcomes associated with internally driven change could occur. Given that the firms of today represent some form of adaptation to "past circumstances, and are therefore never in full accord with the requirements of the present" (Veblen, 1925:191), the challenge of 
survival depends upon the minimization of the maladjustment between firm's phenotype (i.e. its activities, products and services, and identity) and the operating environment. Clearly, the firm's learning capabilities are critical to enabling continual safe passage through the environment's corridor of fitness. The 'corridor of fitness' concept refers to the degrees of freedom afforded the firm's activities, products and services and identity by the operating environment. The proposition being that no desirable equilibrium position exists (or is possible), but rather the relative degree of environmental stability determines the breadth of a buffer zone within which degrees of fitness are achieved. The proposition being that no identifiable equilibrium position exists (or is possible in reality), but rather the relative degree of environmental stability determines the breadth of a buffer zone within which degrees of fitness are achieved. Bruderer and Singh (1996) suggest that instead of assuming an (either/or) equilibrium position exists, firms are guided by continual feedback through which they adjust their interacting elements to achieve a higher degree of organizational fitness.

The task at hand is to explain how a Darwinian theory could unite both Lamarckian (internal) and Weismannian (external) selection pressures and explain the process of evolution across both stable and unstable market conditions. That is, to explore the proposition that internal and external selection processes are indeed "fundamentally interrelated processes of change" (Levinthal, 1991:144). Also, to move away from past assumptions where managers are conceived as rational actors capable of interpreting and controlling their environment. In this paper, adaptive behaviours (related to firm change) are viewed as experimental 'trial-and-error' incursions into tomorrow. These behaviours are context specific and the product of interaction between human nature and the environment. The outcomes of such behaviours are unpredictable, but reconcilable through the generic evolutionary processes of variation, selection, and retention.

In unstable markets, the role of the human is central to the idea of Darwinian variations being seen as "trial-and-error learning events" in which either positive or negative outcomes are just as probable (McKelvey, 1994:321). The key is to remain within the boundaries of the corridor of fitness. It is suggested that in reality some firms continually conduct behavioural trials, whereas those that don't may have little ability in this regard to adjust their phenotype, especially during unstable markets. What may be worse is that some firms may also remove themselves from a competitive position within stable markets through an inability to conduct sensible behavioural trials. Before discussing the nature of such learning processes, it is appropriate to now consider other issues that must be considered through proposing a unified Darwinian theory.

\section{THE QUEST FOR CAUSALITY}

A philosophical creed at the centre at the heart of Darwinism focuses upon "the problem of causality" (Hodgson, 2003b:87). Yet, the development of many evolutionary approaches does not enable articulation or appreciation of a process demonstrating cumulative causation. Despite the acknowledged significance of Nelson and Winter's (1982) seminal work, they proposed ${ }^{2}$ routines to be both genotypes (i.e. operating routines) and phenotypes (i.e. manifest behaviours) that act

\footnotetext{
${ }^{2}$ It is noted by Hodgson (2003a) that both Nelson and Winter (via separate personal correspondence with Hodgson) acknowledge that routines are more like genotypes than phenotypes, or physical behaviours.
} 
as both behavioural dispositions and actual behaviours. From an evolutionary perspective, this is an unworkable proposition given that routines cannot be both the generative structures (i.e. replicators) and the outcomes of such structures (i.e. interactors) (Hodgson, 2003a). Aldrich (1999) also seeks to make a significant contribution to the development of an evolutionary approach to organization evolution, but importantly, fails to explicitly identify replicators and interactors. As such, the critical relationship between interacting phenotypes and preserved or rejected replicating processes is not clear. Hull (1988) notes that the underlying processes that support replication and interaction are fundamentally different. Clearly it is not possible to develop an evolutionary theory that has explanatory power in the absence of accurately defining these two components.

A Darwinian theory concerns a process of change within which natural selection has a major (but not exclusive) role to play. Darwin himself noted, "that natural selection has been the most important, but not the exclusive, means of modification" (1901:4). Therefore, an evolutionary theory must also address the occurrence of variations associated with adaptive behaviours within evolving systems. A Lamarckian role is accepted on the proviso that "acquired characters are inherited only rarely and weakly" (Gould, 2002:354) relative to the process of natural selection. Gould notes Darwin's acceptance of such a possible secondary role (to natural selection) for Lamarckism. Further, a unified Darwinian theory that features both Lamarckism and Weismannism must account for Durham's (1991) five requirements of evolution; 1) the units of transmission; 2) the sources variation; 3) mechanisms of transmission; 4) processes of transmission; and 5) sources of isolation. Lastly, in accepting the presence of selection mechanisms acting from within the firm, the entities that are the replicators and interactors must be identified (Knudsen, 2002).

The identification of what constitutes replicators and interactors will be dealt with first. In the biotic sense, evolution is determined by the ongoing process of genotypes (i.e. genes) determining the structure of phenotypes (i.e. organisms) that interact, replicate and whose subsequent form is constantly subject to the process of natural selection (Hodgson, 2001). The process of genetic variation is random and therefore not Lamarckian. However, from a socio-economic perspective, routines (Nelson \& Winter, 1982; Knudsen, 2002) and/or habits (Hodgson, 2001) are akin to genotypes, with the firm (and all components of its physical form) representative of the phenotype. Variation is introduced as a result of the firm's interaction (e.g. experience and learning) within the operating environment. Valued characteristics can be acquired by copying and retained through repeated performance.

The definition of replicators by Hull (1988:408) as any "entity that passes on its structure largely intact in successive replications" is widely accepted. Hodgson (2003a) stresses that while there is no direct equivalent in the socio-economic domain that corresponds to genes or genotypes, individual habits and organizational routines adequately describe the entities that produce replication. This point of view is anchored by a specific argument that requires habits and routines to be seen as behavioural dispositions that under particular conditions give rise to particular events. Murmann (2003) states that Durham's (1991) units of transmission and mechanisms of transmission can be viewed as replicators, while the processes of transmission can be viewed as the means of interaction. The definition of interactors by Hull (1998:408) as any "entity that interacts as a cohesive whole with its environment in such a way that this interaction causes replication to be differential" is also widely accepted. However, it is difficult to ascertain from the literature exactly what interacts with the environment. 


\section{THE ELEMENTS OF PHENOTYPIC INTERACTION}

Not surprisingly, the relationship between these two basic models of minimal evolutionary explanations appears incomplete. This section aims to consider the Durham (1991) and Hull (1998) positions by establishing what is acceptable as a replicators and interactors. There appears consensus, or at least convincing arguments $^{3}$ within the literature that habits and routines are suitable as units of transmission. Also, we can account for sources of organizational variation through the means of innovation, copying and new entrants. It would seem reasonable to accept that the process of transmission is related to the interaction of entities within an ecological hierarchy (Baum \& Singh, 1994) that consists in descending order of; the ecosystem, communities of practice, populations of firms, individual firms, work groups, and jobs. What appears to be missing is a plausible explanation of the mechanism of transmission that goes beyond mere acceptance of learning and explains the outcomes pertaining to related replicating and interacting entities. Indeed, Knudsen (2002:451) highlights the need "to account for the mechanism of transmission and the infusion of new but not limited variation around the mean of what turned out to provide an advantage".

The challenge that remains for any evolutionary explanation "is to specify how variants are introduced, how selection leaves behind variants that were not as fit according to the prevailing selection criteria (criteria that in turn need to be identified), and how some variants are retained over time to create a historical trajectory or genealogy captured by decent with modification" (Murmann, 2003:11). However, again there appears to be an absence of focus upon what element/s of the firm is interacting with the environment. If the position of Hodgson (2003a) is taken, and habits and routines are taken as replicators, the question remains, what interacts? Firms of all sizes are characterised by the following three dimensions: goal-directed behaviours, Boundary maintenance, and activity systems (Aldrich, 1999). From this perspective, why and where interaction occurs is accounted for respectively by the firm's goals and boundaries. However, the activity systems of a firm cannot simply be considered as the interactor. Aldrich notes that activity systems are comprised of sets of routines and bundles of activities that facilitate the processing of raw materials, information and people. However, the question now arises, which activities are performed outside the firm and therefore interact with the environment, and which are performed inside and don't interact with the environment?

Within the services marketing literature, Grove and Fisk (1983) have successfully applied Goffman's (1959) dramaturgy approach to establish interaction boundaries using the frontstage, backstage metaphor. The use of the metaphor encourages exploration of the suggested relationship between two phenomena (i.e. the service provider and their audience). While it is seen that the interaction takes place on the front stage, the outcomes of such interaction is dependent upon the degree of rehearsed planning, design and implementation (completed backstage). The challenge remains to separate front stage from back stage, and to define what was visibly offered for consumption by the firm. Just as important is to establish which backstage processes (despite their invisibility) determined the nature of the performance. During the latter stages of this paper this metaphor will be revisited and relied upon to explain the relationship between replicating and interacting entities.

\footnotetext{
${ }^{3}$ See Hodgson (2003a; 2001) regarding the respective merits of memes, ideas, habits, and routines as replicating entities.
} 
If this challenge is resolved, then we can move beyond assuming the firm's entire activity system interacts with its operating environment. We can see the proposition that the market selects and removes firms that have insufficient profits (Murmann, 2003), while true, is an after the event description of what has been selected. It is more likely that specific elements of the firm's performance (rejected on the front stage) have caused insufficient profits. Therefore, a focus on interacting entities must move beyond activity systems, but not extend immediately to entire firms. What must be considered is the actual nature of what is offered for consumption. It is proposed that what constitutes the firm's offerings could be considered, a combination of activities that are delivered by humans and technologies, actual products and services, and the identity of the firm. These three elements, while not representing an exhaustive search for all possible offerings provide elements of focus. Through them, we can see how change is enacted within the firm through modification to existing goals, boundaries and activities, and we have material elements whose consumption (i.e. marketplace acceptance) can be measured.

The firm's three interacting elements are now briefly considered in more detail. While a combination of activities that are delivered by humans and technologies seems broad in description, we can be more specific. This first element relates to all contact points through which the firm and its agents interact with all external stakeholder groups. The actual services and products the firm provides should require no further explanation as an element through which firm/stakeholder interaction occurs. The last proposed element is that of identity. Identity has previously been considered an interactor (Knudsen, 2002:461) with regards to "the personal and professional identity of team members". However, the proposed role of identity considered here is at the higher level of the firm itself. The literature tends to use the phase "corporate identity' (Stuart, 1997) to describe corporate personality, which is based upon corporate strategy. Here, the term 'corporate' will be used interchangeably with 'firm' to reflect the broad application of the evolutionary ideas expressed. Therefore, the identity of a firm embodies its culture and personality and a function of its interaction with external stakeholders is the firm's image. This image influences the firm's fitness within its operating environment.

So, in summary, before we move on to the role of learning, lets recap what ideas have so far been considered. The transformation of firms and populations typically results from seemingly different forms of evolution, natural selection and adaptation. Too many these processes have remained mutually exclusive. However, together they can both be explained through application of Darwinian theory. At the heart of Darwinian theory lies a need to establish cause and effect of cumulative change. However, previous evolutionary models do not always allow appreciation of change occurring in systems as a result of processes of transformation. It has been argued that identification of which entities are replicating and which are interacting would advance the explanatory power of evolutionary theories. Through accepting Hodgson's (2003a) argument that routines cannot be both replicators and interactors, replicators are viewed as habits and routines. Interactors were then considered to be a combination of the activities that are delivered on the front stage by humans and technologies, actual products and services, and the identity of the firm. As illustrated within Figure 1, these three interacting elements of the firm are reconcilable through the introduction of a baseline where the firm's offerings are favoured or rejected by the operating environment within which its operations occur. What remains unexplained is how the firm's learning processes relate to existing perceptions and knowledge and market feedback through which such offerings are altered or unaltered. The following section utilizes the construct absorptive capacity to 
demonstrate a possible mechanism of transmission through which the final composition of such offering can be contemplated from an evolutionary perspective.

\section{Figure 1: Replicating and Interacting Entities}

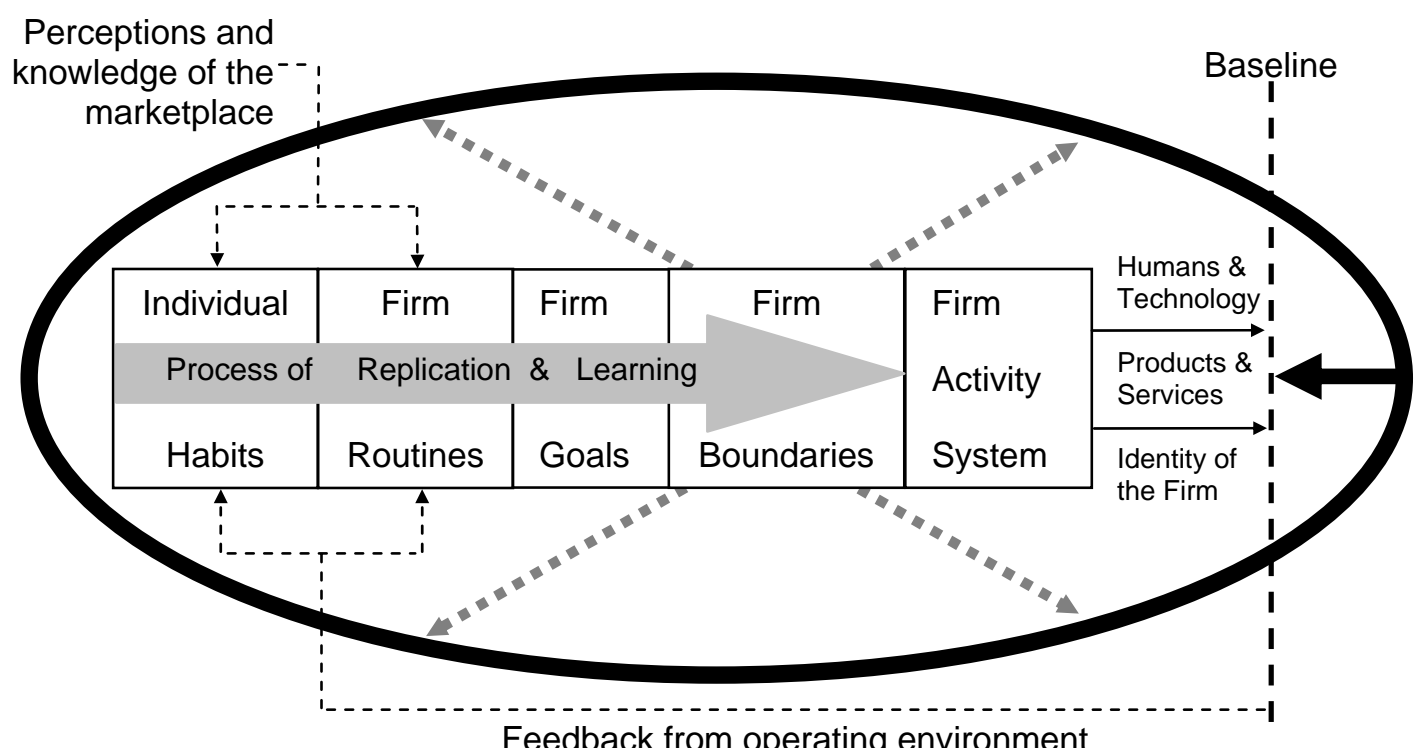

\section{A MECHANISM OF TRANSMISSION}

It will be argued that the construct absorptive capacity, as recently reconceptualized by Zahra and George (2002), provides a mechanism through which the process of replication and its relationship to interacting entities can be explained. Such explanation can be achieved through subsuming the process of learning within and across the generic evolutionary processes of variation, selection, and retention. The major task according to Durham (1991:24) is to identify what "governs the transmission of units [i.e. habits and routines] through space and time and either maintains or erodes variability". But first, we must consider the nature of absorptive capacity as a construct.

Since the seminal contribution of Cohen and Levinthal (1990), absorptive capacity has been associated with the acquisition and use of knowledge to enhance firm performance through increased learning and innovation (e.g. Keller, 1996; Liu \& White, 1997; Kim, 1998). Cohen and Levinthal defined absorptive capacity as the "ability to recognize the value of new information, assimilate it, and apply it to commercial ends (1990:128). Originally operationalized as a single factor component with three dimensions (i.e. valuing, assimilating, and applying new knowledge), the potential influence of absorptive capacity was understood to be dependent upon the firm's prior knowledge base and skills. However, in their reconceptualization, Zahra and George (2002:186) define absorptive capacity as having two distinct components that together are operationalized as "a set of organizational routines and processes by which firms acquire, assimilate, transform, and exploit knowledge to produce a dynamic organizational capability" (2002:186).

Within this new definition are two specific components, potential (i.e. acquisition and assimilation) and realized (i.e. transformation and exploitation) absorptive capacity. 
Potential absorptive capacity is the capability to sense what information is relevant, acquire it, analysis it, comprehend it and internalise it. As such, it provides the firm an appreciation of the exogenous environmental forces that may or may not favour the firm's existing offerings. Realized absorptive capacity relates to the processes that blend existing knowledge with newly acquired knowledge to gain new insights to opportunities or problems and provide structured pathways to develop new competencies. In aggregate, the two components potential provide the foundation of "a dynamic capability pertaining to knowledge creation and utilization" (Zahra \& George, 2002:185). When viewed from an evolutionary perspective, it is argued that this interpretation of the absorptive capacity construct supports discussion of how, why, and when individual firms learn about environmental change. The construct also appears to fit with Hodgson's (2003a) habits and routines as replicators approach.

The four dimensions of absorptive capacity; acquisition, assimilation, transformation, and exploitation, can be seen to be present as potential behaviours. These potential capabilities are triggered by external or internal events that cause to the firm to respond to the stimuli. That is, the firm's ability to efficiently acquire and assimilate external knowledge is a function of their past capability to perform such behaviours under the same context and selective pressures. However, this learning potential only influences the firm's evolutionary potential (Jones, 2003) if all four dimensions coexist as a cohesive whole. Merely increasing awareness of variations does not endow the firm with the ability to maintain or increase the fitness of the interacting phenotype. Thus, the firm is subject to selection at two specific levels. First, the interacting phenotype faces the pressures of natural selection, and secondly, this interaction results in the differential selection of the habits / routines that support the replicating processes within the firm. Given that firm's can acquire new characteristics from the marketplace, the firm's degree of potential absorptive capacity shapes up as critical to the process of adapting to market shocks and exploiting opportunities. Importantly, this capability is mediated by the degree of prior knowledge held across specific domains.

Campbell (1965:27) states that if all components of the variation-selection-retention process are present, "a socio-cultural learning process is inevitable". Clearly, the absorptive capacity construct must illustrate a process dependent upon all three components to effectively act as a mechanism of transmission in an evolutionary sense. Learning is described within an organizational setting as, outcomes related to change via analysis or imitation, or, a process of adaptation dependent upon delicately balancing exploration against exploitation (March, 1991). This suggests that to achieve learning dependent outcomes, both variation and retention processes must relate to each, despite the inherent forces that alienate each from the other. The ability of firms to select new variations (or retain existing variations) clearly shapes the nature of the phenotypic interaction. However, to use an adaptation of Aristotle's approach to the use of anger, any firm can change - that is easy. But to change the right activity systems, to the right degree, at the right time, for the right purpose, and in the right way - that is not easy. To further explore this issue, first we need to again consider Knudsen's (2002) baseline idea.

The firm's activity systems represent behaviours that produce products and services, are responsible for the development of a firm's identity, and facilitate contact between the firm's systems (be they human of technological) and external stakeholders. In short, they are responsible for what occurs of the front stage. This performance is dependent upon the potential capabilities of the firm to plan, revise, and implement such behaviour. At anytime, the firm is in receipt of feedback from its audience. The market share achieved by products and services, the image present in the 
marketplace of the firm, and information received during contact between the staff and/or technological interface all represents substantial and ongoing feedback. This feedback should act to stimulate further planning, revision, and implementation of future performance. This activity is performed on the back stage and guided by the pressures of natural selection that are real and present on the front stage. This pressure should provide guidance to the adaptive intentions of the firm. The process of internal selection, a function of the habits and routines present within the firm, is ultimately judged by the audience on the front stage.

What emerges from this discussion is the need for the habits and routines of the firm to have the potential to act in harmony throughout all four behavioural dimensions of the absorptive capacity construct. The efficiency between exploration and exploitation is determined by the nature of the habits and routines that support initially the acquisition and assimilation of external knowledge, and then the transformation and exploitation of knowledge. This continuity of potential behaviours is crucial given that the process of socio-economic evolution is dependent upon the interplay between interacting and replicating entities (Baum \& Singh, 1994). Working against this desirable process are internal and external forces that differentially influence the development of potential absorptive capacity and the realized absorptive capacity. Given that the realized absorptive capacity is the primary source of adaptive improvements (Zahra \& George, 2002), it is clearly important to consider impediments to the cumulative process that enables exploration and subsequent exploitation.

For example, it is possible that habits and routines imprinted into firms (Tucker, Singh \& Meinhard, 1990) at founding will not support optimal learning. Such inadequacies may allow internal selection criteria to acts "as vicarious representatives of past external criteria" (Aldrich, 1999:27). So it is important to identify and isolate the habits and routines associated with the intensity, speed, and direction related to collecting external knowledge. It is also important to understand how existing knowledge bases influence the future development of external knowledge. In the event, that a firm is trying to acquire and assimilate external knowledge that is new and novel, the existing technological paradigm (Dosi, 1984) may limit comprehension of such knowledge. Clearly in both circumstances variation is present, but the selection of favoured variations would seem as dependent upon luck as any other factor.

The degree and frequency of change previously undertaken also provides clues as to the existence of habits and routines that have the potential to assist the firm's baseline deliberations. Behind all manner of decision making within firms lay processes and routines that expose the decision makers to perceptions of their environment, be they flawed or accurate (Smircich \& Stubbart, 1985). A challenge exists to balance such perceptions against the feedback related to the interacting phenotype and act in a way that maintains or increases fitness of the firm vis-à-vis its operating environment. Given that misperceptions related to the activity system and marketplace are common (Langlois, 1997), the trial-and-error approach affords firms a buffer against extreme maladjustment. This is especially so when the nature of change within the operating environment is unpredictable (McKelvey, 1994).

Lastly, it should be possible to identify the existence of frequently performed behaviours that support the exploitation of favourable learning outcomes. These would provide evidence of the bundled routines contained within the firm's activity systems that provide structured pathways to sustain the exploitation of knowledge over time. So, the proposed mechanism of transmission, absorptive capacity, provides a framework through which to identify the presence of habits and routines 
that will engage the variation-selection-retention process. This in turn would provide insight into the cause and effect relationships between habits and routines, learning processes, changes to the firm's goals, boundaries, and activity systems, and the phenotype interacting with the operating environment.

\section{CONCLUSION}

This paper has sought to outline the preliminary development of a framework for unifying the two main evolutionary perspectives commonly used in organizational studies. While it is messy to simultaneously work with Lamarckian, Neo-Darwinian, Darwinian, and Weismannian terminologies, it is deemed necessary to establish the basic properties of a pure Darwinian theory of socio-economic transformation. Without identifying the cumulative processes of cause and effect, an evolutionary theory remains an incomplete means of analysis, rather than a potential empirical tool. At the heart of this challenge is the need to bring the minimal requirements of an evolutionary theory to account. Here, attention has been given to the works of Campbell (1965), Hull (1988), and Durham (1991) in this regard. The construct absorptive capacity has been utilized to provide a structure within which the evolutionary scaffolding (Hodgson, 2003a) of Darwinism can be constructed.

What is required beyond the frameworks further development is to enable the rigorous explanatory power of Darwinism to be placed within an empirical context. For example, an investigation of the processes relating to organizational change. Such research would aim to observe the proposed role of absorptive capacity to coordinate, mediate, and therefore influence the processes of replication and interaction. Within this emerging research agenda is an underlying need to explain the existence of any Lamarckian mechanism of transmission responsible for acquired characteristics being learnt and retransmitted (Baum \& Singh, 1994). Given that the presence of natural selection pressures are taken as given, observing the interplay between both selection pressures operating through a baseline would provide justification for increasingly employing a Darwinian, rather than solely a neoDarwinian or Lamarckian approach.

\section{REFERENCES}

Aldrich, H.E. (1999), Organizations Evolving, Sage Publications, London.

Amburgey, T.L., Kelly, D. and Barnett, W.P. (1993) "Resetting the clock: The dynamics of organizational change", Administrative Science Quarterly, Vol 38 No 1.

Baum, J.A.C. and Singh, J.V. (1994), "Organizational hierarchies and evolutionary processes: Some reflections on a theory of organizational evolution", in Baum, J.A.C. and Singh, J.V. (Eds.), Evolutionary Dynamics of Organizations, Oxford University Press, New York.

Bruderer, E. and Singh, J.T. (1996) "Organizational evolution, learning, and selection: A genetic-algorithm-based model", Academy of Management Journal, Vol 39 No 5.

Campbell, D.T. (1965), "Variation and selective retention in socio-cultural evolution", in Barringer, H.R., Blanksten, G.I. and Mack, R.W. (Eds.), Social Change in Developing Areas: A Reinterpretation of Evolutionary Theory, Schenkman Publishing, Cambridge. 
Cohen, W.M. and Levinthal, D.A. (1990) "Absorptive capacity: A new perspective on learning and innovation", Administrative Science Quarterly, Vol 35 March.

Darwin, C. (1901), The Origin of Species by Means of Natural Selection, J. Murray, London.

Dosi, G. (1984), Technical Change and Industrial Transformation, MacMillin Press, Hong Kong.

Durham, W.H. (1991), Coevolution: Genes, Culture, and Human Diversity, Stanford University Press, California.

Goffman, E. (1959), The Presentation of Self in Everyday Life, Doubleday, Garden City, NY.

Gould, S.J. (2002), The Structure of Evolutionary Theory, Harvard University Press, London.

Grove, S.J. and Fisk, R.P. (1983), "The dramaturgy of services exchange: An analytical framework for services marketing", in Berry, L.L., Shostack, G.L. and Upah, G.D. (Eds.), Emerging Perspectives on Services Marketing, American Marketing Association, Chicago, IL.

Hannan, M.T. and Freeman, J. (1989), Organizational Ecology, Harvard University Press, Cambridge, Massachusetts.

Haveman, H.A. (1992) "Between a rock and a hard place: Organizational change and performance under conditions of fundamental environmental transformation", Administrative Science Quarterly, Vol 37 No 1.

Hodgson, G.M. (1993), Economics and Evolution: Bringing Life Back into Economics, Polity Press, Cambridge, UK.

Hodgson, G.M. (2001), "Is social evolution Lamarckian or Darwinian", in J. Nightingale, J. and Laurent, J. (Eds.), Darwinism and Evolutionary Economics, Edward Elgar, Cheltenham.

Hodgson, G.M. (2003a) "The mystery of the routine: The Darwinian destiny of an evolutionary theory of economic change", Revue Economique, Vol 54 No 2.

Hodgson, G.M. (2003b) "Darwinism and institutional economics", Journal of Economic Issues, Vol 37 No 1.

Hull, D.L. (1988), Science as a Process: An Evolutionary Account of the Social and Conceptual Development of Science, University of Chicago Press, Chicago.

Jones, C (2003) "Beyond e-commerce: When caterpillars know what butterflies understand", Journal of New Business Ideas and Trends, Vol 1 No 2.

Keller, W. (1996) "Absorptive capacity: On the creation and acquisition of technology in development", Journal of Developmental Economics, Vol 49 No 1.

Kim, L. (1998) "Crisis construction and organizational learning: Capability learning in catching-up at Hyundai Motor", Organization Science, Vol 9 No 4. 
Knudsen, T. (2001), "Nesting Lamarckism with Darwinian explanations: Necessity in economics and possibility in biology", in Nightingale, J. and Laurent, J. (Eds.), Darwinism and Evolutionary Economics, Edward Elgar, Cheltenham.

Knudsen, T. (2002) "Economic selection theory", Journal of Evolutionary Economics, Vol 12 No 4.

Langlois, R.N. (1997), "Cognition and capabilities: Opportunities seized and missed in the history of the computer industry", in Garud, R., Nayyar, P. and Shapira, Z. (Eds.), Technological Innovation, Cambridge University Press, New York.

Levinthal, D.A. (1991) "Organizational adaptation and environmental selection: Interrelated processes of change", Organization Science, Vol 2 No 1.

Liu, X. and White, R.S. (1997) "The relative contributions of foreign technology and domestic inputs to innovation in Chinese manufacturing industries", Technovation, Vol 17 No 3.

McKelvey, B. (1994), "Evolution and organizational science", in Baum, J.A.C. and Singh, J.V. (Eds.), Evolutionary Dynamics of Organizations, Oxford University Press, New York.

Malthus, T.R. (1826), An Essay on the Principle of Population, Murray, London.

March, J.G. (1991) "Exploration and exploitation in organizational learning", Organization Science, Vol 2 No 1.

Murmann, J.P. (2003), Knowledge and Competitive Advantage, Cambridge University Press, New York.

Nelson, R.R. and Winter, S.G. (1982), An Evolutionary Theory of Economic Change, Harvard University Press, Cambridge.

Smircich, L. and Stubbart, C. (1985) "Strategic management in a enacted world", Academy of Management Review, Vol 10 No 4.

Stuart, H. (1997) "Exploring the corporate identity / corporate image interface: An empirical study of accountancy firms", Journal of Communication Management, Vol 2 No 4.

Tucker, D.J., Singh, J.V. and Meinhard, A.G. (1990), "Founding characteristics, imprinting, and organizational change", in Singh, J.V. (Ed.), Organizational Evolution: New Directions, Sage Publications, London.

Veblen, T. (1925), The Theory of the Leisure Class, George Allen \& Unwin, London.

Wilkins. J.S. (2001), "The appearance of Lamarckism in the evolution of culture", in Nightingale, J. and Laurent, J. (Eds.), Darwinism and Evolutionary Economics, Edward Elgar, Cheltenham.

Zahra, S.A. and George, G. (2002) "Absorptive capacity: A review, reconceptualization, and extension", Academy of Management Review, Vol 27 No 2. 